\title{
Philosophical Foundations of the Concept of Green Economy
}

\author{
Vitaly Ivlev \\ Department of Philosophy \\ Bauman Moscow State Technical University \\ Financial University under the Government of Russian \\ Federation \\ (Financial University) \\ Moscow, Russia \\ E-mail: vitalijivlev@yandex.ru
}

\author{
Marina Ivleva \\ Department of History and Philosophy \\ Plekhanov Russian University of Economics \\ Moscow, Russia \\ E-mail: stm602@yandex.ru
}

\begin{abstract}
The article investigates the initial philosophical principles of the green economy concept, which is one of the modern promising approaches in economic science. The authors analyze the essence of the green economy, describe a retrospective of its conceptual development. They come to the conclusion that the philosophical foundations of the concept of green economy are based on the philosophical principles of systemness and integrity, the principle of eco-centrism, and the ethics of bio-centrism; consider the place of the concept of the ecological imperative in researches of green economy; analyze the understanding of the world as the ecological and economic system in the concept of green economy.
\end{abstract}

Keywords-green economy; system; holism; integrity; systemness; biocentric ethics; coevolution; sustainable development

\section{INTRODUCTION}

At present, innovative information economy is developing all over the world. If previously in the economic activities environmental factor was not in the scope of research, and wasteful use of natural resources has led to irreparable consequences, post-industrial information economy is based on the environmental factors. Now the ecology aspect is one of the dominant problems among the priority tasks to overcome the negative effects of the global economy. The formation of a new economy determines new challenges for science to overcome the existing negative phenomena in the world economy.

Such a trend of modern economic theory and practice as "green" economy contributed to the solution of these problems. Currently, the "green economy" is one of the most popular areas of development of economic practice. At the same time, in the context of the new economy formation, many issues of the theory and practice of considering environmental factors in investment, in the workplace in order to ensure sustainable development in market conditions have not been resolved at the moment and require further study and research, both in the field of economic and social Sciences. The relevance of the "green economy" entails the need for its philosophical justification, identifying its place and role in the development of modern social life.

Green economy is a trend in economic science, which asserts that economics is a dependent component of the natural environment within which it exists. The concept of "green economy" is the most important theoretical and practical approach to the solution of the modern ecological problem within the framework of the sustainable development theory. This term and approach in economic science appeared relatively recently-about four decades ago. This approach is based on three fundamental principles: 1) mutual dependence of all life on the planet, 2) the refusal of the requirement to meet the ever-growing needs in a limited number of resources, 3 ) the refusal of the endless expansion in a limited space.

The concept of "green economy" aims to establish a more harmonious coexistence of nature and society. The current economic model, according to representatives of the green economy, is ineffective. Improving the material wellbeing of certain groups of the world's population, it causes environmental problems such as loss of biological diversity, depletion of natural capital, climate change, widespread poverty. All this determines a real threat not only to the present, but also to future generations, and the concept of "green economy" is very important in order to ensure the harmonious development of mankind. In this scales of green economy the production, distribution and consumption of goods will improve the well-being of a man, even in the long term and will not determine negative environmental impacts.

\section{EvOlution STUdies OF "GREEN" ECONOMY IN THE WRITINGS OF SCHOLARS}

Russian scientist V. I. Vernadsky made a significant scientific contribution to the development of scientific theories of economic activity ecologization. In 1926 V. I. Vernadsky published the work "Biosphere", in which he marked the birth of a new science about nature and its connection with man. The next stage in the formation of the ecological economy as a science began in 1935, when A. 
Tansley introduced a new definition of "ecosystem", which meant a set of living organisms (communities) and their habitat, a sustainable system of life, formed in the process of circulation of substances [1]. The starting point of modern social ecology was the publishing the book by R. Carson's "Silent spring" (1961), which deals with negative environmental effects in the process of human activities [2].

Ecology as a science is the theoretical basis of environmental protection and rational use of natural resources. One of the founders of theory about the relationship of nature and human economic activity from the standpoint of environmental science was American scientist B. Commoner. He formulated the laws of ecology in 1971, as four basic principles, which the sustainable development of nature and call on mankind to be guided by them in their influence on the environment.

Principle one: "Everything is Connected to Everything Else"; in the tradition of the dialectical materialistic position of the universal connection of things and phenomena, it means that the living dynamics of complex ecological chains form a single system;

Principle two: "Everything Must Go Somewhere"; here, to paraphrase the fundamental physical law of conservation of matter, the Commoner raises one of the most difficult problems of applied ecology - the problem of the biosphere assimilation of human civilization wastes;

The third principle: "Nature Knows Best"; in contrast to the traditional approach, initiated by FrancisBacon, according to which nature is a workshop, and people use nature for their purposes, taking into account only its own interests, - this law is associated with the call to care. and caution in dealing with natural ecosystems;

Principle four: "There is No Such Thing as a free Lunch", according to the Commoner, since the global ecosystem is a single whole, everything that has been extracted from it by human labor should be reimbursed [3].

In the $80 \mathrm{~s}$ of the twentieth century the philosophy of ecological economics is formed as an integral part of the concept of green economy. It emerged as an alternative to an environmental economy, as an approach that aimed to comprehend and solve the problems associated with the interaction of the environment and society. Among the most famous representatives there wereR. Costanza, R. H. Daly, Norgaard, J. Van den Berg [4], [5], [6], [7]. Ecologicaleconomics is a new interdisciplinary field of research that focuses on the relationship between ecosystems and economic systems. This theory, based on an interdisciplinary approach, combined the ideas of economics, philosophy, ecology, and other natural and social sciences, having absorbed the most useful features of traditional economic theory and traditional ecology.

\section{THE PRINCIPLE OF SYSTEMNESS AS A BASIC PHILOSOPHICAL PRINCIPLE OF GREEN ECONOMY}

One of the basic philosophical principles that determine the adequacy of the human cognition of the surrounding reality is the principle of systemness. This principle application in modern scientific knowledge makes it possible to reflect the real relationships among the objects and phenomena around us, their interdependence and interaction. The principle of systemness represents the essence of "green economy", as it supposes its functioning as a complex dynamic system formed as an integral set of interacting subsystems.

The set of interconnected, integrating and complementary systems, namely, the economy, society and the environment, is an internal, stable qualitative basis of the green economy. These systems ensure the reproduction of natural factors and conditions to meet the needs and activities of man, based on a balance in constant interaction with each other.

The ecological economy establishes a new model, where the economic system is a part of society, which, in turn, is a subsystem of nature, a general ecosystem. One of the founders of the theory of ecological economics, R. Costanza, claims that it includes a description of the relationship between dynamic economic systems and larger dynamic, but normally slower-changing ecological systems [8]. Thus, in the ecological economy, the economy is an open subsystem of a larger ecosystem. Since the ecosystem is a constant, it is necessary to pay attention to the use of natural resources in the economy and the absorption capacity of the ecosystem with respect to the losses that it incurs because of its use in economic processes.

Continuous feedback between the economic system and the ecosystem gives each of them the opportunity to develop - and, according to R. Norgaard, this is the essence of coevolution [9]. From this point of view, it becomes obvious that the tasks of the economy should correspond to the tasks of the environment, and not vice versa. And, besides the fact that the economy depends on the resources of the ecosystem, it cannot exist without people, therefore physical, emotional and spiritual health, as well as social, or "social" capital of people, determine the economic results. In turn, such health is affected by attributes or characteristics of the ecosystem.

The social subsystem as a whole is the result of the life processes of human society. In their social orientation, the interests of the economic system are united with the interests of the ecological system development: the nature of this unity is expressed in the fact that the set of systemic interests is aimed at achieving a certain quality of human life as a subject of the social system, guaranteeing the status of life, and at ensuring the biological and material independence of a person in society.

The basis for the formation and development of the green economy is the environmental system. Such approach is determined first of all by the fact of relative independence of ecological system functioning from economic activity of the person: in biological sense, the person is an element of the nature. The ecological system is a closed, self-sufficient and self-developing system, which has a clear hierarchical structure and constant laws of its development. Without the intervention of human activities ecosystem is able to maintain equilibrium in its conditional balance. 
The basic nature of the ecological system in the structure of the green economy is determined by the fact that it is an external environment and resource support for the functioning of the economic and social systems. This phenomenon is expressed in functional modifications of the environment, which is asserted as a public consumer good, a source of production resources, an object for waste disposal and a place for the location of economic objects.

The dialectical contradictory character of the green economy components, such as ecological, economic and social systems, is based on the fact that the interests of ecology require absolute constancy of the natural environment, whereas the interests of the economic system, the implementation of which is due to the objectives of meeting the increasing material and spiritual needs of society, require increasing the range and scale of environmental impact, which subsequently, if the interests of the ecological system are not respected, destroys its integrity and violates the natural balance [10].

The interaction of the social economy with nature is contradictory by itself. By contributing to the development of society and the satisfaction of human needs, the economic and social system acts as a disintegrator of the natural environment of its habitat. In order to overcome this inconsistency, the green economy theory formulated the concept of sustainable development as a process of economic and social change, in which the exploitation of natural resources, the direction of investment, the orientation of scientific and technological development, the development of personality and institutional changes are coordinated with each other and strengthen the current and future potential to meet human needs and aspirations. This concept is one of the fundamental in the structure of the theory of green economy and expresses the main goal of socio-economic development of modern society.

\section{THE PRINCIPLE OF INTEGRITY AS A BASIC PHILOSOPHICAL PRINCIPLE OF GREEN ECONOMY}

The methodology of holism, which is the philosophy of organic integrity as a unifying substance of the world, is fundamental to reveal the paradigm of the noosphere ecology and culture. It transforms the categorical apparatus of philosophy and the content of its certain fundamental categories, in such a way, that not only systems, but also organic integrity, space, harmony are investigated in the center of philosophic research.

Green economy, as a scientific theoretical approach has significant peculiaritiers in comparison with both traditional trends of economic theory and traditional ecology. While the first focuses on the tools of the economic system, the ecological economy is a more holistic approach to explain the processes and phenomena which occur in the economic sphere [11]. In turn, when comparing the theory of green economy and traditional ecology, common theoretical prerequisites, such as the traditions of holism, and understanding nature as a set of ecosystems, are obvious; but the green economy goes further, studying not only the natural but also the social world in a holistic unity, placing at the forefront the values of life and nature as such.

The understanding of the natural world around us as a whole, the integral subsystems of which are society and economy, human integration into this structure, consideration of the elements of economy and society in inseparable unity - these are the essential features of the theory of green economy based on ecophilosophy A. Næss, a Norwegian philosopher. He formulated ecophilosophical principles in his speech in Bucharest at the 3rd World Future research conference, which took place in September 1972.He postulated the idea that in fact the ecological movement is philosophical, and ecology, as a science, is inspired by philosophy, as the most broad, general scope for debate on values and normative issues. The most popular became the summary of the speech, published as an article in the journal "Inquiry" in 1973, entitled "The Shallow and the Deep LongRange Ecology Movement: a Summary" [12]. By the term "eco-philosophy", Naess means the philosophy of ecological harmony, or equilibrium, which ainvestigates classical ecological problems from the point of view of a systemic approach, from the point of view of the equal value of nature and man in the world, with the requirement to combine the means of ecology and social philosophy to achieve this harmony.

Deep ecology is characterized by several special features.

This is a denial of the common understanding of a man as a person within the environment, and appeal to the image of a great whole, which is the result of complex relationships where living organisms are "nodules" of the biosphere network. Thus, the deep ecology rejects in general any concept of "object in environment", replacing it with a holistically determined understanding of the internally interconnected whole.

It is the adoption of the natural diversity principles, which supports the survival potential of the world as a whole, and symbiosis as the starting point for coexistence and life of biological forms. Proceeding from the principle of the integrity of the world, Naess notes that the principle of diversity is equally the starting point in our understanding of the diversity of co-existing ways of people life, their cultures, professions, economic approaches.

According to Naess, the struggle against environmental pollution and resource depletion should not be separated from the overall holistic system of the world, and should take into account the possible negative consequences of individual actions, such as the rising cost of good living conditions and the stratification of society.

Holistic approach to the problem of interaction between man and nature proposed by Naess, transformed into a broader and more comprehensive eco-philosophical approach, which investigated the problem of the interaction between man and the world as a whole, in the unity of its biological, social and spiritual factors.

Eco-philosophical and holistic paradigm, according to which the world exists as an open, complex, self-developing integrity, which is studied at the level of the universal in the 
context of the preservation of planetary existence in the unity of man with culture, society, nature and space, is a promising perspective. Such integrity is represented not only by the set and variety of its elements, processes and forms of horizontal development, but also as a hierarchy of integrity and their constituent subsystems.

\section{THE ETHICAL COMPONENT OF THE CONCEPT OF "GREEN ECONOMY"}

The ethical element, due to the comprehensive nature of ethics as a science about morality, has become one of the most important in the modern trend of humanization of modern society. The concept of green economy, which raises questions of existence and survival of man and nature in modern conditions, and sustainable development of society, is characterized by an important ethical component in its philosophical foundations. In a situation where the problem of environmental crisis has become the subject of scientists' attention, in recent decades philosophy of ecology has become popular as a humanistic ideology aimed at preserving and maintaining the value of human life and nature as a whole.

The concept of "green economy" is determined by the ethical principle of eco-centrism, which implies the need to preserve the biosphere as a natural basis of life on Earth and is based on the recognition of the equivalence of the natural world and civilization, and necessity of their mutual development (coevolution). This concept is based on the biocentric ethics, according to which nature has the original internal value, it is valuable by itself, as life in general and the space of life existence. Man is an important but not the only element of nature, and as such the value of nature prevails over the value of the time-and space-limited goals and needs of man.

Within the framework of biocentric ethics are all the fundamental concepts and principles of green economy, including the concept of sustainable development, which includes meeting the needs of the present generation, without jeopardizing the ability of future generations to meet their own needs. This definition implies the creation of a socioeconomic system that will ensure not only a high standard of living for the long term, but also its quality: the growth of real incomes, the improvement of the educational level, the improvement of health and the environment, the reduction of social and environmental risks, social guarantees and benefits.

Exploring the philosophical and ethical aspects of the environmental problem, Russian scientist N. H. Moiseev introduces the concept of "ecological imperative", the essence of which is to use and implement only those technologies and methods of human activity that do not destroy the conjugacy of the natural biogeochemical cycles of the Earth. The scientist emphasized that this system of norms and rules should not contradict the laws of the biosphere and the relations established in it, it should take them into account and contribute to their preservation [13].

In the framework of the ecological imperative one of the key actions in the organization of the harmonious development of society and nature becomes a scientific regulation of biological species (including man) within the ecological niches they occupy; the activities and behavior of mankind within acceptable limits; regulation of man's relationship with all the components of his social and natural environment; plants, resource flows, fertility, consumption, social protection, etc. The ecologization of the mankind consciousness is connected with the comprehension of the need for this regulation. The understanding of this regultion deep meaning is the source for comprehension of new value orientations of mankind which form new ideological attitudes and new character of needs of the person motivating the aspirations to ecologically reasonable activity and behavior.

The ecological imperative becomes the basis for the formation of a new social ideology, a new social policy, morality and ethics, and the problem of natural and ecological becomes the element of the socio-cultural sphere.

\section{CONCLUSION}

In general, the philosophy of the green economy follows the scientific principle of eco-centrism, which takes into account the biosphere as the basis of life and asserts the equivalence of nature and society as elements of the general ecosystem, the need for their joint development, coevolution.

The results of the analysis of approaches to the green economy indicate the dominance of a systematic approach in understanding the essence of this category, which reflects the unity of the two components: the environment and the economy, which are in relationships with each other, forming a certain integrity within the framework of a holistic approach.

A systematic approach, in our opinion, as a scientific point of view, is the most complete for understanding the essence of the ecosystem, since it involves the functioning of the green economy as a complex dynamic system, formed as a complete set of interconnected ecological and economic systems [14]. This approach reflects in its totality integrated, factorial and functional approaches to understanding the essence of the green economy, which is expressed in the concept of "system".

It is important to take into account that the economic and environmental spheres are systems, each of which operates on the basis of certain laws and is characterized by an individual conceptual and terminological apparatus, as well as a set of factors and laws that determine their development. Interacting, ecological and economic systems form system of the new order, namely ecological and economic system which will be inherent not only properties of subsystems forming it (ecology and economy), but also creates the new set of characteristics. From the point of view of the system approach, the ecological and economic system is the external environment of the coevolution interaction of the ecological, social and economic systems, synthesizing the integration of the "evolutionary-economic" and "evolutionary-ecological" systems. The idea of a joint, mutually dependent evolution is important both for biological and economic processes. After all, the lack of resources - both in biology and in the 
economy - generates the limits of space-time development of the relevant system, the types of interaction and feedback mechanism between the elements of these systems. It is the coevolution approach to the essence of the ecological and economic system that gives an understanding of the principles of one subsystem development with a deterministic effect on the development of another subsystem.

\section{REFERENCES}

[1] A. G. Tansley. The use and abuse of vegetational concepts and terms / A. G. Tansley // Ecology. - 1935. - № 3. - Vol. 16. - P. 284-307.

[2] R. Carson. Silent Spring / R. Carson. Boston: Houghton Mifflin. Reprinted, 1961.

[3] B. Commoner. The closing circle: Nature, Man, and Technology. New York, 1971

[4] R. Costanza (ed). Ecological economics: the science and management of sustainability. - Columbia University Press, New York. - 1991.- pp. $8-9$

[5] H.E. Daly. Beyond growth. The economics of sustainable development. Boston, 1996.

[6] R. Norgaard (1984). Coevolutionary development potential // Land Economics. 60 (2) pp. 160-173

[7] J.C.J.M. van der Bergh. Ecological economics and sustainable development: Theory, methods and application. Edward Elgar, Cheltenham, 1996.

[8] R. Costanza (ed). Ecological economics: the science and management of sustainability. - Columbia University Press, New York. - 1991.- pp. 8-9

[9] R. Norgaard(1994). Development Betrayed: The End of Progress and a Coevolutionary Revisioning of the Future. Routledge, London

[10] Gr. Epstein. Missing ecology: integrating ecological perspectives with the social-ecological system framework / Gr. Epstein // International journal of the Commons. - 2013. - Vol. 7. - P. 432-453.

[11] M.I.Ivleva,I.V.Yablochkina,I.M.Kornilova,S.D.Lyudvig,B.S. Vasyakin. Ecological aspect of investment projects for the development of specially protected nature territories (by the example of the Sochi national park) // Research Journal of Pharmaceutical, Biological and Chemical Sciences. 2016. T. 7. № 4. C. 1293-1303.

[12] A. Naess. The Shallow and the Deep Long-Range Ecology Movement: A Summary. // Inquiry. Vol.16. № 1. - P. 99 -100.;

[13] N.N. Moiseev.Chelovek i noosfera. Moskva, Molodayagvardiya, 1990.

[14] V.Ivlev,M. Oseledchik. Methodological principles for the introduction of modality categories in modern scientific cognition. 3rd international conference on arts, design and contemporary education (ICADCE 2017). 2017. C. 541-545. 